\title{
Genome-wide expression patterns associated with oncogenesis and sarcomatous transdifferentation of cholangiocarcinoma
}

Min-A Seol ${ }^{1 \dagger}$, In-Sun Chu ${ }^{3+}$, Mi-Jin Lee ${ }^{1}$, Goung-Ran Yu' ${ }^{1}$ Xiang-Dan Cui ${ }^{1}$, Baik-Hwan Cho ${ }^{2}$, Eun-Kyung Ahn ${ }^{4}$, Sun-Hee Leem ${ }^{4}$, In-Hee Kim, Dae-Ghon Kim ${ }^{1 *}$

\begin{abstract}
Background: The molecular mechanisms of CC (cholangiocarcinoma) oncogenesis and progression are poorly understood. This study aimed to determine the genome-wide expression of genes related to CC oncogenesis and sarcomatous transdifferentiation.

Methods: Genes that were differentially expressed between CC cell lines or tissues and cultured normal biliary epithelial (NBE) cells were identified using DNA microarray technology. Expressions were validated in human CC tissues and cells.

Results: Using unsupervised hierarchical clustering analysis of the cell line and tissue samples, we identified a set of 342 commonly regulated ( $>2$-fold change) genes. Of these, 53 , including tumor-related genes, were upregulated, and 289, including tumor suppressor genes, were downregulated $(<0.5$ fold change). Expression of SPP1, EFNB2, E2F2, IRX3, PTTG1, PPAR $\gamma$, KRT17, UCHL1, IGFBP7 and SPARC proteins was immunohistochemically verified in human and hamster CC tissues. Additional unsupervised hierarchical clustering analysis of sarcomatoid CC cells compared to three adenocarcinomatous CC cell lines revealed 292 differentially upregulated genes ( $>4$ fold change), and 267 differentially downregulated genes ( $<0.25$ fold change). The expression of 12 proteins was validated in the CC cell lines by immunoblot analysis and immunohistochemical staining. Of the proteins analyzed, we found upregulation of the expression of the epithelial-mesenchymal transition (EMT)-related proteins VIM and TWIST1, and restoration of the methylation-silenced proteins LDHB, BNIP3, UCHL1, and NPTX2 during sarcomatoid transdifferentiation of CC.
\end{abstract}

Conclusion: The deregulation of oncogenes, tumor suppressor genes, and methylation-related genes may be useful in identifying molecular targets for CC diagnosis and prognosis.

\section{Background}

Cholangiocarcinoma $(\mathrm{CC})$ is a highly lethal adenocarcinoma arising from bile duct epithelial cells. CC accounts for approximately $15 \%$ of the total liver cancer cases worldwide, and its incidence is rising [1,2]. The prognosis for CC is quite poor because of difficulties in early diagnosis, and relative resistance of the tumors to chemotherapy $[3,4]$. At the time of diagnosis, approximately

\footnotetext{
* Correspondence: daeghon@chonbuk.ac.kr

+ Contributed equally

'Division of Gastroenterology and Hepatology, the Institute for Medical Science, Departments of Internal Medicine, Chonbuk National University

Medical School and Hospital, Jeonju, Jeonbuk, South Korea

Full list of author information is available at the end of the article
}

$70 \%$ of CC patients have an occult metastasis or advanced local disease that precludes curative resection. Of candidates for curative resection, 30\% develop recurrent disease at the anastomotic site or within the intrahepatic biliary tree, and succumb to disease progression or cholangitis [5]. Established risk factors for ductal cholangiocarcinomas include primary sclerosing cholangitis, infection with Clonorchis sinensis or Opisthorchis viverrini (liver flukes), Calori's disease, congenital choledochal cysts, and chronic intrahepatic lithiasis [6]. However, for most CCs, the cause is unknown.

Recently, molecular investigations have provided evidence that $\mathrm{CC}$ carcinogenesis involves a number of

\section{C) Biomed Central}


genetic alterations, including activating point mutations in the K-ras oncogene, and in $p 53$ and BRAF [7-9]. The deregulated expression of a number of other genes has also been reported, and cyclooxygenase- 2 and c-erbB-2 are frequently overexpressed in CCs, suggesting an involvement in early biliary carcinogenesis [10]. In addition, increased expression of interleukin- 6 is frequently observed in CC [11]. CC also develops after the liverspecific targeted disruption of the tumor suppressors SMAD4 and PTEN [12]. The incidence of sarcomatoid changes in $C C$ is estimated to be approximately 5\% [13], and sarcomatoid cells are thought to result from de-differentiation of ordinary carcinomatous CC cells. Sarcomatoid neoplasms are highly aggressive and have a poorer survival rate than ordinary CCs [14], but the underlying molecular alterations, which may be related to the epithelial-mesenchymal transition (EMT), remain unclear. Little extensive genome-wide information about altered gene expression in CCs is available, and only a few published studies have reported a comprehensive analysis of gene expression among biliary tract cancers in general $[15,16]$. The advancement of microarray technology now enables us to analyze genome-wide gene expression in a single experiment, opening avenues for the molecular classification of tumors, detection of the biological nature of tumors, and prediction of prognosis and sensitivity to treatments.

In this study, we generated genome-wide gene expression profiles of 10 cell lines ( $9 \mathrm{CC}$ cell lines and 1 immortalized cholangiocyte line), and $19 \mathrm{CC}$ tissues using a BeadChip oligonucleotide technology containing 48,000 genes. This procedure allowed us to observe a comprehensive pattern of gene expression in CC compared to cultured normal biliary epithelia (NBE). In addition, we identified a set of genes associated with sarcomatoid transdifferentiation. These data are useful not only because they provide a more profound understanding of cholangiocarcinogenesis and transdifferentiation, but also because they may help to develop diagnostic tools and improve the accuracy of $\mathrm{CC}$ prognosis.

\section{Methods}

\section{Cell lines and cultures}

Tumor tissues were obtained from surgical specimens and biopsy specimens in Korean cholangiocarcinoma patients. Tumor tissues were washed three times in Opti-MEM I (Gibco, Grand Island, NY) containing antibiotics. Washed tissue was transferred to a sterile Petri dish and finely minced with scalpels into 1 - to $2-\mathrm{mm}^{3}$ fragments. Tissue fragments in culture medium were seeded in T25 culture flasks (Corning, Medfield, MA) in Opti-MEM supplemented with $10 \%$ fetal bovine serum (FBS, Gibco), 30-mM sodium bicarbonate and antibiotics. Tumor cells were cultured undisturbed and passaged as described [17]. Near the 20th passage, the medium was changed from Opti-MEM I to DMEM supplemented with $10 \%$ FBS and antibiotics. NBE cells were isolated from mucosal slices of normal bile ducts, with informed consent from liver transplantation donors, and ex-vivo cultured in T25 culture flasks in Opti-MEM supplemented with $10 \% \mathrm{FBS}, 30 \mathrm{mM}$ sodium bicarbonate and antibiotics at $37^{\circ} \mathrm{C}$ with $5 \% \mathrm{CO}_{2}$ in air. Near-confluent NBE cells were harvested and stored at $-80^{\circ} \mathrm{C}$ until use. Cells were routinely tested for mycoplasma and found to be negative using a Gen Probe kit (San Diego, CA). CC cell lines are in Table 1.

\section{5-Aza-2'-deoxycytidine (Aza) treatment}

Choi-CK, Cho-CK, and JCK cells were seeded at $1 \times 10^{6}$ cells $/ \mathrm{ml}$. After overnight culture, cells were treated with $5 \mu \mathrm{M}$ of the DNA methylating agent Aza (SigmaAldrich, St. Louis, MO) for 4 days, and then harvested.

\section{Patients and tissue samples}

$\mathrm{CC}$ tissues were obtained with informed consent from Korean patients who underwent hepatectomy and common bile duct exploration at Chonbuk National University Hospital. All tumors were clinically and histologically diagnosed as cholangiocarcinoma. Detailed clinocopathological data of the 19 samples are in Table 2. All samples were immediately frozen in nitrogen tanks. Patient information was obtained from medical records. Clinical stage was determined according to the International HepatoPancreato-Biliary Association (IHPBA) classification [18].

Primer labeling and Illumina Beadchip array hybridization Total RNA from CC samples was isolated using TRIzol reagent (Invitrogen, $\mathrm{CA}$ ) according to the manufacturer's instructions. RNA quality was determined by gel electrophoresis, and concentrations were determined using an Ultrospec 3100 pro spectrophotometer (Amersham Bioscience, Buckinghamshire, UK). Biotin-labeled cRNA samples for hybridization were prepared according to Illumina's recommended sample-labeling procedure: $500 \mathrm{ng}$ of total RNA was used for cDNA synthesis, followed by an amplification/labeling step (in vitro transcription) to synthesize biotin-labeled cRNA using the Illumina TotalPrep RNA Amplification kit (Ambion Inc., Austin, TX). cRNA concentrations were measured by the RiboGreen method (Quant-iT RiboGreen RNA assay kit; Invitrogen-Molecular Probes, ON, Canada) using a Victor3 spectrophotometer (PerkinElmer, CT), and cRNA quality was determined on a $1 \%$ agarose gel. Labeled, amplified material (1500 ng per array) was hybridized to Illumina Human-6 BeadChips v2 containing 48,701 probes for 24,498 genes, according to the manufacturer's instructions (Illumina, San Diego, CA). Array signals were developed by Amersham fluorolink streptavidin-Cy3 (GE 
Table 1 Clinicopathological features of nine patients with intrahepatic cholangiocarcinomas used to generate CC cells lines

\begin{tabular}{|c|c|c|c|c|c|c|c|}
\hline Patient No & Cell line & Age/Sex & T/N/M Stage & CA19-9 (U/ml) & Differentiation & Tumori genicity & Comments \\
\hline 1 & CK-Choi (Choi-CK) & $M / 68$ & IVB & 184 & WD & + & \\
\hline 2 & CK-Cho (Cho-CK) & M/82 & IVA & 500 & $\mathrm{MD}$ & + & \\
\hline 3 & CK-J (JCK) & $M / 72$ & IVA & 125 & PD & + & C. sinensis \\
\hline 4 & CK-S (SCK) & $M / 68$ & IVA & 235.6 & PD & + & Sarcomatoid \\
\hline 5 & CK-L1 & $M / 46$ & IVA & 0.01 & PD & + & Combined with $\mathrm{HCC}$ \\
\hline 6 & CK-L2 & $M / 65$ & III & 2050.1 & $\mathrm{MD}$ & + & \\
\hline 7 & CK-P1 & M/66 & IVA & 23.7 & $\mathrm{MD}$ & - & \\
\hline 8 & CK-P2 & $F / 66$ & IVA & 121.4 & $\mathrm{MD}$ & + & \\
\hline 9 & CK-Y1 & $M / 52$ & IVA & 0.01 & PD & + & Combined with HCC \\
\hline
\end{tabular}

M, male; F, female; C. sinensis, clonorchis sinensis; HCC, hepatocellular carcinoma; WD, well differentiated; MD, moderately differentiated; PD, poorly differentiated.

*International Hepato-Pancreato-Biliary Association classification.

Healthcare Bio-Sciences, Little Chalfont, UK) following the BeadChip manual. Arrays were scanned with an Illumina Bead-array Reader confocal scanner (BeadStation 500GXDW; Illumina) according to the manufacturer's instructions. Array data processing and analysis were performed using Illumina BeadStudio software. The BeadStudio Gene Expression Module is a tool for analyzing gene expression data from scanned microarray images generated by the Illumina BeadArray Reader.

\section{Data analysis}

Normalization algorithms were used to adjust sample signals to minimize the effects of variation from non- biological factors. To reduce variation between microarrays, the intensity values for samples in each microarray were rescaled using a quartile normalization method in the BeadStudio module. Measured gene expression values were log2-transformed and median-centered across genes and samples for further analysis. To generate an overview of the gene expression profile and to identify major relationships in cell lines, we used unsupervised hierarchical clustering analysis. Genes with an expression ratio of at least a two-fold difference relative to the median gene expression level across all samples in at least $10 \%$ of samples were selected for clustering analysis. Average linkage hierarchical cluster analysis was carried out using a

Table 2 Clinicopathological features of 19 CC samples used for microarray analysis

\begin{tabular}{|c|c|c|c|c|c|c|c|c|c|c|c|}
\hline Sample No & Age/Sex & Loca tion & Size $(\mathrm{cm})$ & $T$ & $\mathrm{~N}$ & $M$ & Stage & Gross appearance & Differentiation & Sub-class & Comment \\
\hline 1 (CC-GHS) & $68 / F$ & L & $8.7 \times 5.4$ & 3 & 1 & 0 & IVA & MF & PD & A & \\
\hline 2 (CC-CYS) & $57 / M$ & L & NA & 3 & 1 & 0 & IVA & $\mathrm{MF}+\mathrm{PDI}$ & MD & A & \\
\hline 3 (CC-LJS) & $42 / M$ & A & NA & 1 & 0 & 0 & । & ID & WD & B & Intraductal papillary \\
\hline 4 (CC-BJP) & $62 / M$ & P & $7.8 \times 5.6$ & 1 & 0 & 0 & 1 & ID & WD & B & Intraductal papillary \\
\hline 5 (CC-HSR) & $66 / M$ & $A P$ & $7.3 \times 6$ & 2 & 0 & 0 & $\|$ & MF & $M D$ & B & \\
\hline $6(\mathrm{CC}-\mathrm{HSW})$ & $59 / M$ & AP & $9 \times 6.8$ & 2 & 0 & 0 & $\|$ & MF & $\mathrm{MD}$ & B & \\
\hline 7 (CC-CSB) & $60 / M$ & L & $4 \times 4.5$ & 3 & 0 & 0 & III & MF & $\mathrm{MD}$ & B & \\
\hline 8 (CC-SJS) & $71 / \mathrm{M}$ & A & $2.1 \times 1.9$ & 1 & 0 & 0 & $\|$ & MF & WD & B & \\
\hline 9 (CC-HDS) & $63 / M$ & $C B D$ & $1.1 \times 0.9$ & 1 & 1 & 1 & IVB & ID & $\mathrm{MD}$ & B & \\
\hline $10(\mathrm{CC}-\mathrm{KHC})$ & $47 / M$ & L & $14 \times 10$ & 4 & 0 & 0 & IVA & MF & PD & C & \\
\hline 11 (CC-LHG) & $42 / M$ & L & $5.6 \times 3.9$ & 3 & 1 & 0 & IVA & MF & PD & C & Combined with $\mathrm{HCC}$ \\
\hline 12 (CC-LSH) & $40 / F$ & $P$ & $8.6 \times 4$ & 2 & 0 & 1 & IVB & MF & PD & C & Combined with $\mathrm{HCC}$ \\
\hline 13 (CC-KHS) & $70 / F$ & L & $8.5 \times 4.8$ & 3 & 0 & 1 & IVB & $\mathrm{MF}+\mathrm{PDI}$ & PD & C & Combined with $\mathrm{HCC}$ \\
\hline 14 (CC-LMS) & $38 / F$ & AP & $5 \times 3.7$ & 4 & 0 & 1 & IVB & MF & PD & C & Combined with $\mathrm{HCC}$ \\
\hline $15(C C-K J A)$ & $39 / F$ & $L P$ & $6 \times 5$ & 4 & 0 & 0 & IVA & MF & $\mathrm{MD}$ & C & Combined with $\mathrm{HCC}$ \\
\hline 16 (CC-JSJ) & $64 / M$ & L & $0.5 \times 0.5$ & 2 & 0 & 1 & IVB & ID & PD & C & \\
\hline 17 (CC-YCU) & $53 / \mathrm{M}$ & L & $4.3 \times 2.1$ & 3 & 1 & 0 & IVA & MF & $\mathrm{MD}$ & C & \\
\hline 18 (CC-GMG) & $50 / \mathrm{M}$ & L & $7 \times 3.5$ & 2 & 0 & 0 & $\|$ & MF & $\mathrm{MD}$ & C & \\
\hline 19 (CC-BSD) & $67 / M$ & L & $2.9 \times 2.7$ & 4 & 0 & 0 & IVA & $M F+P Q$ & PD & C & \\
\hline
\end{tabular}

HCC, hepatocellular carcinoma; M, male; F, female; A, anterior segment; $\mathrm{P}$, posterior segment; Med, medial segment; $L$, lateral segment; MF, mass forming type; PDI, periductal infiltrating type; IDG, intraductal growth type; WD, well differentiated; MD, moderately differentiated; PD, poorly differentiated; NA, not available. *International Hepato-Pancreato-Biliary Association classification. 
Pearson correlation as the similarity metric, using the GeneCluster/TreeView program (http://rana.lbl.gov/EisenSoftware.htm). Expression profiles for the differentially expressed genes were selected by $t$-test with false discovery rate (FDR) and q-values as gene significance measures, using $\mathrm{R}$ software (version 2.5). Because of varying significance in the analyzed comparisons, using a fixed FDR (or q-value) cut-off value was not practical. Therefore, we used $t$-test $P=0.01$. To ascertain biological relevance, a fold-change cut-off value of 2 or 4 from the mean was chosen. The gene ontology (GO) program (http://david. abcc.ncifcrf.gov/) was used to categorize genes in subgroups based on biological function. Values for each GO group were calculated as a percentage of total mRNA change. For example, the Fisher exact test was used to determine whether the proportions of genes in each category differed by group. The microarray data were registered with the Gene Expression Omnibus (GEO) database (Accession No. GSE22633)

\section{Immunoblotting}

Extracted protein $(30 \mu \mathrm{g})$ from cell lysates was resolved by SDS-PAGE and transferred to a nitrocellulose membrane. Membranes were incubated for $1 \mathrm{~h}$ at room temperature with primary antibody at 1:1000 dilution. After incubation, blots were washed three times in TBS/0.1\% Tween 20. Immunoreactivity was detected using alkaline phosphatase-conjugated goat anti-rabbit IgG or a commercial chemiluminescence detection kit (Amersham), according to the manufacturer's instructions.

\section{Immunohistochemistry}

Immunohistochemical staining was performed on formalin-fixed, paraffin-embedded $4-\mu \mathrm{M}$ tissue sections, as described preciously [19]. Briefly, a deparaffinized section was pretreated by microwave epitope retrieval (750 W during $15 \mathrm{~min}$ in citrate buffer $10 \mathrm{mmol}$; pH 6.0) after rehydration. Before applying primary antibodies, the endogenous peroxidase activity was inhibited with $3 \%$ hydrogen peroxide, and a blocking step with biotin and bovine albumin was performed. Primary monoclonal or polyclonal antibodies were detected using a secondary biotinylated antibody and a streptavidinhorseradish peroxidase conjugate according to the manufacturer's instructions (DAKO, Glostrup, Denmark). Counterstaining was performed using Meyer's hematoxylin. Tumors were evaluated for the percentage of positive cells and the staining intensity. Negative controls were samples incubated with either PBS or mouse IgG $_{1}$ instead of primary antibody.

\section{Real-time RT-PCR}

RNA prepared from dissected tissues was precipitated with isopropanol and dissolved in DEPC-treated distilled water. Reverse transcription (RT) was performed using $2 \mu \mathrm{g}$ total RNA, $50 \mu \mathrm{M}$ decamer and $1 \mu \mathrm{l}$ (200 units) and RT-PCR Superscript II (Invitrogen) at $37^{\circ} \mathrm{C}$ for $50 \mathrm{~min}$, as previously described. Specific primers for each gene were designed using the Primerdepot website (http://primerdepot.nci.nih.gov/) and are in Additional file 1. The control $18 S$ ribosomal RNA primer was from Applied Biosystems (Foster City, CA) and was used as the invariant control. The real-time RT-PCR reaction mixture consisted of $10 \mathrm{ng}$ reverse-transcribed total RNA, $167 \mathrm{nM}$ forward and reverse primers, and $2 \times \mathrm{PCR}$ master mixture in a final volume of $10 \mu \mathrm{l} \mathrm{PCR}$, was in 384-well plates using the ABI Prism 7900HT Sequence Detection System (Applied Biosystems).

\section{Animal model of cholangiocarcinoma}

The hamster CC model was modified from a previous study [20]. On the first day of the experiment, hamsters in the experimental group were infected with 15 metacercariae of the liver fluke, $C$. sinensis. One day after parasite infestation, hamsters received $15 \mathrm{ppm}$ of dimethylnitrosamine (DMN; Kasei, Japan) in the drinking water for 4 weeks with a normal diet. Thereafter, hamsters were given tap water with a normal diet for the rest of the study. An interim stage of cholangiocarcinogenesis was confirmed at 8 weeks after experiment initiation. Control and CC model hamsters were maintained for a total of 27 weeks for $\mathrm{CC}$ to develop.

\section{Results}

\section{Gene expression patterns distinguish CC cells from cultured NBE cells}

Using BeadChip microarray analysis, we compared the gene expression profiles of nine $\mathrm{CC}$ cell lines, an immortalized biliary epithelial cell line, and four types of NBE cells. We selected 828 unique genes with a 2 -fold or greater expression difference from the mean, with a $P<0.01$ by $t$-test. Unsupervised hierarchical clustering analysis of all samples was based on the similarity in the expression pattern of all genes (Figure 1). Cell samples were separated into two main groups, the NBE cluster, and the transformed and immortalized biliary epithelial cells (CCC cluster). Each distinctive gene cluster was identified by delineation using a hierarchical clustering dendrogram. Cluster I consisted of genes upregulated in $\mathrm{CC}$ cells, which included tumor-related genes such as LGR4, AGR2, PCAF, TMEM97, FRAT2, EFNB2 and ZIC2 [21-27]. Cluster II included genes underexpressed in CC cells. These were mainly tumor suppressor genes such as GREM1, THY1, STC2, SERPINE1, SPARC and TAGLN [28-33]. Cluster III was genes upregulated in NBE cells, and contained the PDGFRA, CD248, and $B D K R B 1$ genes. 


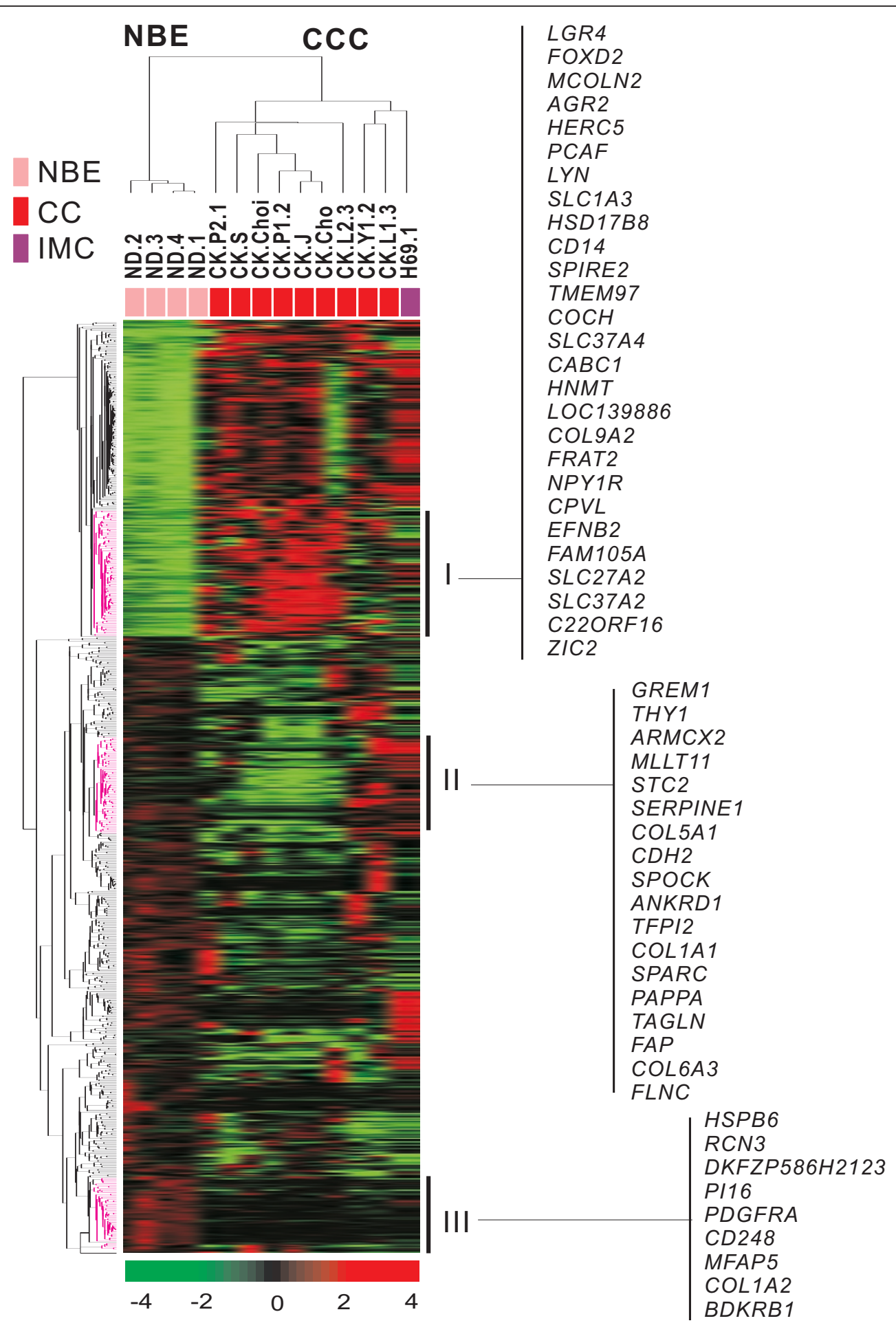

Figure 1 Unsupervised hierarchical clustering of four biliary epithelial cells, one immortalized cholangiocyte cell line and nine CC cells Unsupervised hierarchical clustering separated the samples into two main groups, normal biliary epithelial cells (NBE) isolated from mucosal slices of normal bile ducts and ex-vivo cultured as described in Methods, and cholangiocarcinoma cells (CCC). Data are in matrix format, with columns representing individual cell lines and rows representing each gene. Red, high expression; green, low expression; black, no significant change in expression level between the mean and sample. A hierarchical clustering algorithm was applied to all cells and genes using the 1 Pearson correlation coefficient as a similarity measure. Raw data for a single array were summarized using Illumina BeadStudio v3.0 and output to the user was as a set of 43,148 values for each individual hybridization. We selected 828 unique genes with a two-fold or greater difference from the mean and $P<0.01$ by $t$-test, for hierarchical clustering analysis. Specific gene clusters (Cluster 1 through Cluster III) were identified in the hierarchical cluster of the genes differentially expressed in CCC compared with NBE. CC, cholangiocarcinoma; IMC, immortalized cholangiocytes. 


\section{Gene expression patterns distinguish CC tissues from cultured NBE cells}

Using BeadChip microarrays, gene expression profiles of 19 CC tissues and 4 types of NBE cells were compared. We selected 1798 unique genes with a 2 -fold or greater differences from the mean difference with a $P<0.01$ by $t$-test. Unsupervised hierarchical clustering analysis was as described above (Figure 2A). All samples separated into two main groups, NBE and CC tissues (CCT). Each distinctive gene cluster was identified using a hierarchical clustering dendrogram as above. Intriguingly, the CC sample cluster was divided into two subclasses by tumor differentiation: differentiated (Df) and undifferentiated (Udf). Clustering data for the $\mathrm{CC}$ group revealed three clusters. Cluster I had genes upregulated in NBE and downregulated in CCT including SERPINB2, PAPPA, LRRC17, and GREM1. Cluster II contained genes upregulated in the Df $\mathrm{CCT}$ and downregulated in NBE. Cluster III included genes upregulated in poorly differentiated or Udf CCT, and downregulated in NBE. A supervised hierarchical clustering analysis was performed between the NBE class, and the Df and the Udf subclasses based on the similarity of expression pattern of all genes (Figure $2 \mathrm{~B}$ and $2 \mathrm{C}$ ). We selected 420 differentially expressed genes in the Df subclass, and 646 genes in the Udf subclass for comparison with the NBE class (Additional files 2 and 3).

\section{Differential expression and verification of CC-related genes}

We compared the gene lists from the cell-based and tissue-based databases, and selected 342 commonly regulated genes, including 53 commonly upregulated genes and 289 commonly downregulated genes (Figure 3A). The top 25 commonly regulated genes in both CCC and CCT compared to NBE are in Additional file 4. To verify the microarray data, we examined the mRNA levels of the identified genes using real-time RT-PCR in human CC tissues. We selected five up-regulated genes from the commonly upregulated genes of both the cell and tissue sample classes (Figure $3 \mathrm{~B}$ ). We also chose the IRX3, PTTG1, and PPAR $\gamma$ genes, which were highly upregulated in only the cell sample class. These genes were preferentially expressed in CC cells and tissues. We also examined the expression of the commonly downregulated KRT17 and UCHL1 genes, as well as the cellular downregulated IGFBP7 and SPARC genes using real-time RT-PCR in human CC. The human NBE showed substantial expression of $C K-17, U C H L 1$, IGFBP7 and SPARC, which were barely detected in CC tissues (Figure 3C).

\section{Immunohistochemical analysis of CC-related genes}

To confirm the reliability of the microarray data and the robustness of the strategy for identifying genes with altered expression, we examined the protein levels of the identified genes using immunohistochemical analysis of human tissues (Figure 4A). We selected three upregulated genes from the genes that were upregulated in both cell and tissue samples. The SPP1, EFNB2 and E2F2 proteins were abnormally overexpressed in the CC cell cytoplasm, and weakly or barely expressed in HCC. We also examined the IRX3, PTTG1, and PPAR $\gamma$ proteins, which were highly upregulated in only the cell samples. IRX3 was the most highly upregulated, and we was strongly expressed in the nucleus of CC cells in the tissue sections, but was barely detectable in the NBE nuclei. PTTG1 and PPAR $\gamma$ were abnormally overexpressed in the CC cell cytoplasm, and their expression was attenuated in poorly differentiated CC. Next, we also used immunohistochemical staining of human CC to examine the KRT17 and UCHL1 proteins, whose genes were both downregulated in CC cells and tissues, and the IGFBP7 and SPARC proteins, which were downregulated in CC cells only. Human NBE showed substantial expression of the CK-17, UCHL1, IGFBP7, and SPARC proteins, but these were barely detectable in $\mathrm{CC}$ tissue. However, KRT-17 was clearly positive in HCC (Figure 4B).

\section{Immunohistochemical analysis in hamster model of CC} Although it is unknown whether antibodies raised to human proteins recognize hamster proteins, we examined the protein levels of the identified genes using immunohistochemical analysis of hamster CC tissues (Additional file 5). As in humans, the SPP1, EFNB2, and E2F2 proteins were abnormally overexpressed in the hamster CC cell cytoplasm. IRX3 was also similarly expressed in the CC cell nucleus, and PTTG1 was differentially expressed in the CC cell cytoplasm. Interestingly, in contrast to human CC cells, PPAR $\gamma$ was preferentially expressed in the hamster CC cell nuclei. Therefore, the immunoreactivity of identified gene proteins in hamster CC seemed to be substantially consistent with that in human CC.

\section{Gene expression patterns distinguish the SCK cell line from three CC cell lines}

Previously, we established four human CC cell lines and characterized one with a typical sarcomatoid phenotype of SCK. We classified the other cell lines according to tumor cell differentition, as a poorly differentiated JCK, a moderately differentiated Cho-CK, and a well-differentiated Choi-CK cell line [34]. Two-way unsupervised hierarchical clustering analysis of quadruplicate samples for each cell line was conducted, based on the similarity of expression patterns of all genes (Figure 5). We selected 559 unique genes whose expression differed from the mean by fourfold or more with $P<0.005$ by $t$-test. Cell samples were 
A

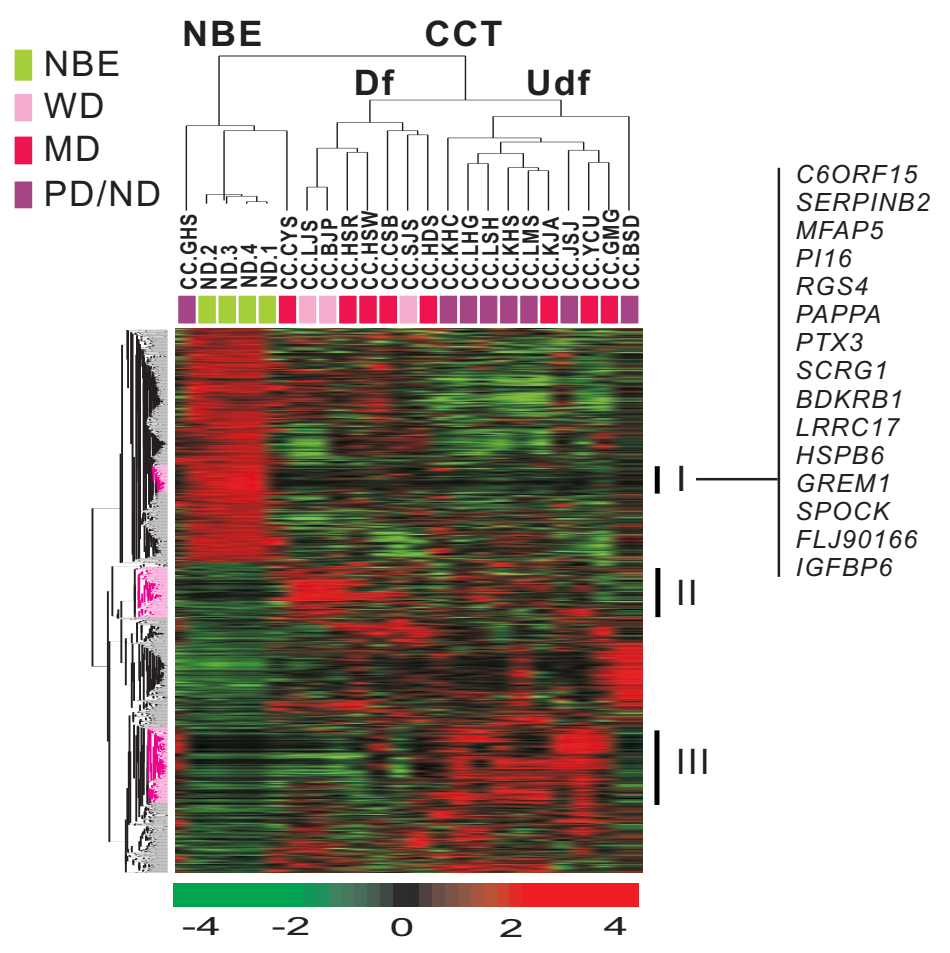

B

C
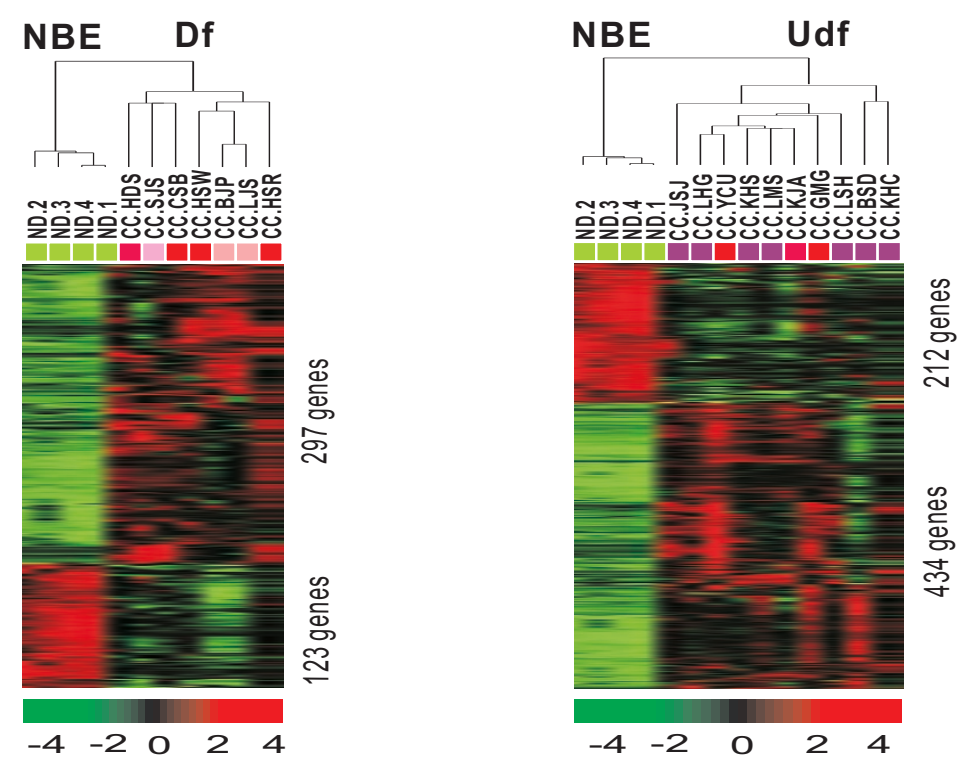

Figure 2 Unsupervised hierarchical clustering of 4 biliary epithelial cells and 19 CC tissues. (A) Unsupervised hierarchical clustering separated the samples into two main groups. We selected 1798 unique genes with two-fold or greater difference from the mean with $P<0.01$ by $t$-test for hierarchical clustering analysis. Specific gene clusters (Cluster 1 through Cluster III) were identified of differentially expressed in CCT compared to NBE. (B) Supervised hierarchical clustering of four biliary epithelial cells and seven differentiated CC tissues. We selected 420 unique genes with four-fold or greater difference from the mean and $P<0.01$ by $t$-test for hierarchical clustering analysis. (C) Supervised hierarchical clustering of 4 biliary epithelial cells and 10 undifferentiated CC tissues. We selected 646 unique genes with the criteria in B for hierarchical clustering analysis. 
A

Differentially expressed genes Upregulated genes
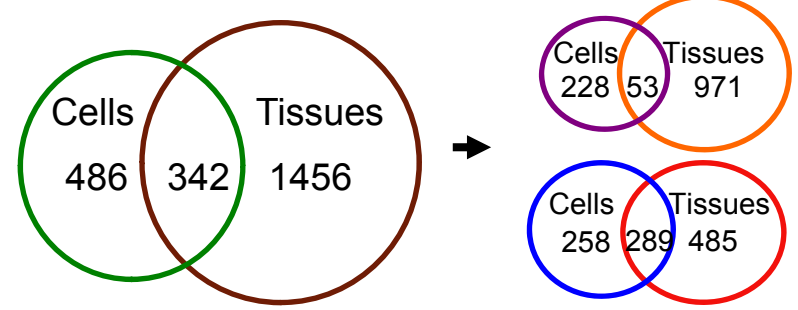

B

Downregulated genes
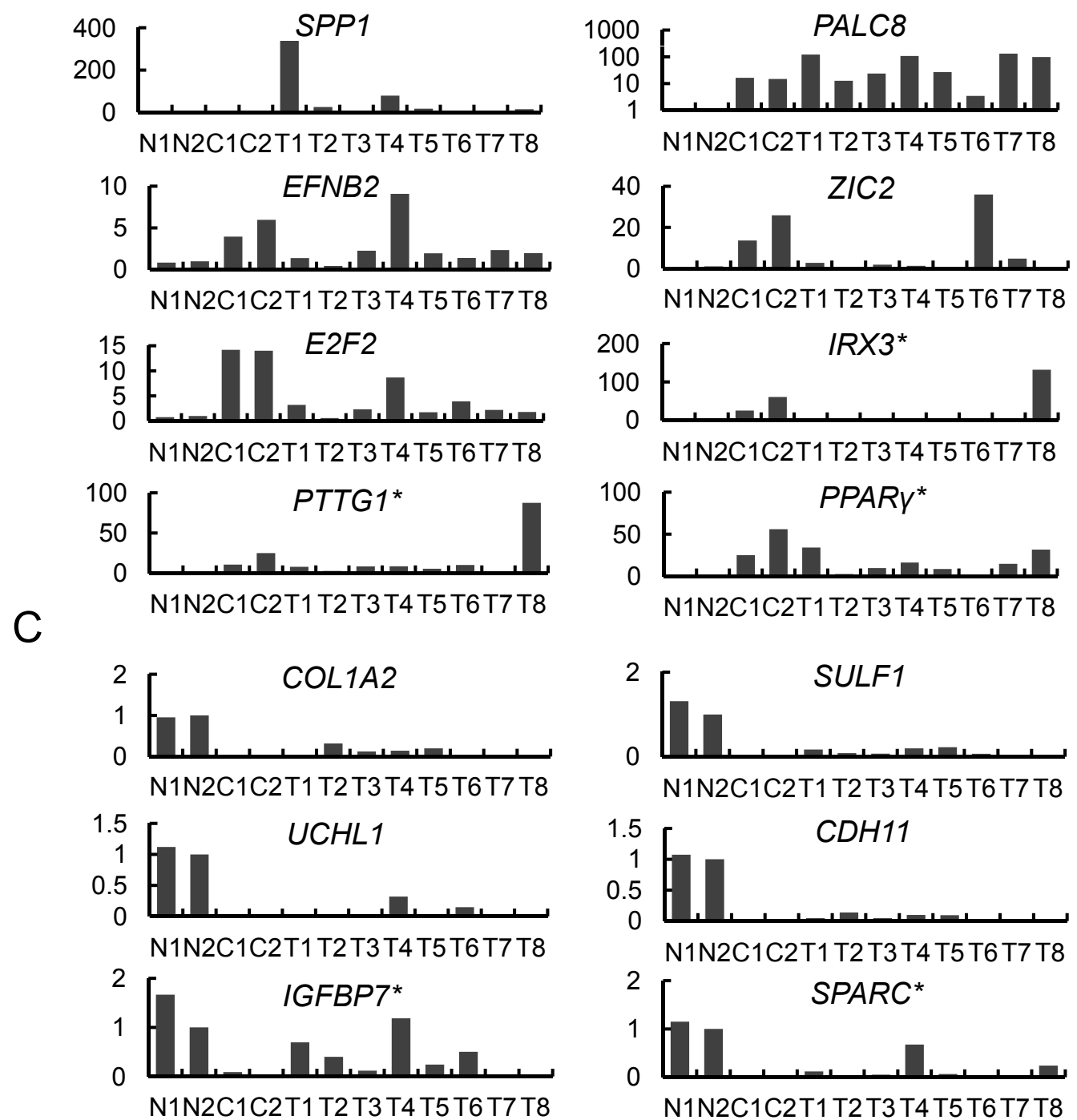

Figure 3 Differentially regulated genes in human CC tissues compared to NBE cells. (A) Venn diagram of genes commonly regulated in the cell and tissue samples. The 342 genes included 53 upregulated and 289 downregulated genes, selected from the cell- and tissue-based microarray databases. (B) Real-time RT-PCR analysis of upregulated genes selected from the list of top 25 genes commonly upregulated in both CC cells (C) and tissues (T) compared to cultured NBE cells (N). *, selected from only the cell-based microarray database. (C) Real-time RT-PCR analysis of downregulated genes selected from the list of top 25 genes commonly downregulated in both CC cells (C) and tissues (T) compared to cultured NBE cells $(\mathrm{N})$. * , selected from only the cell-based microarray database. 


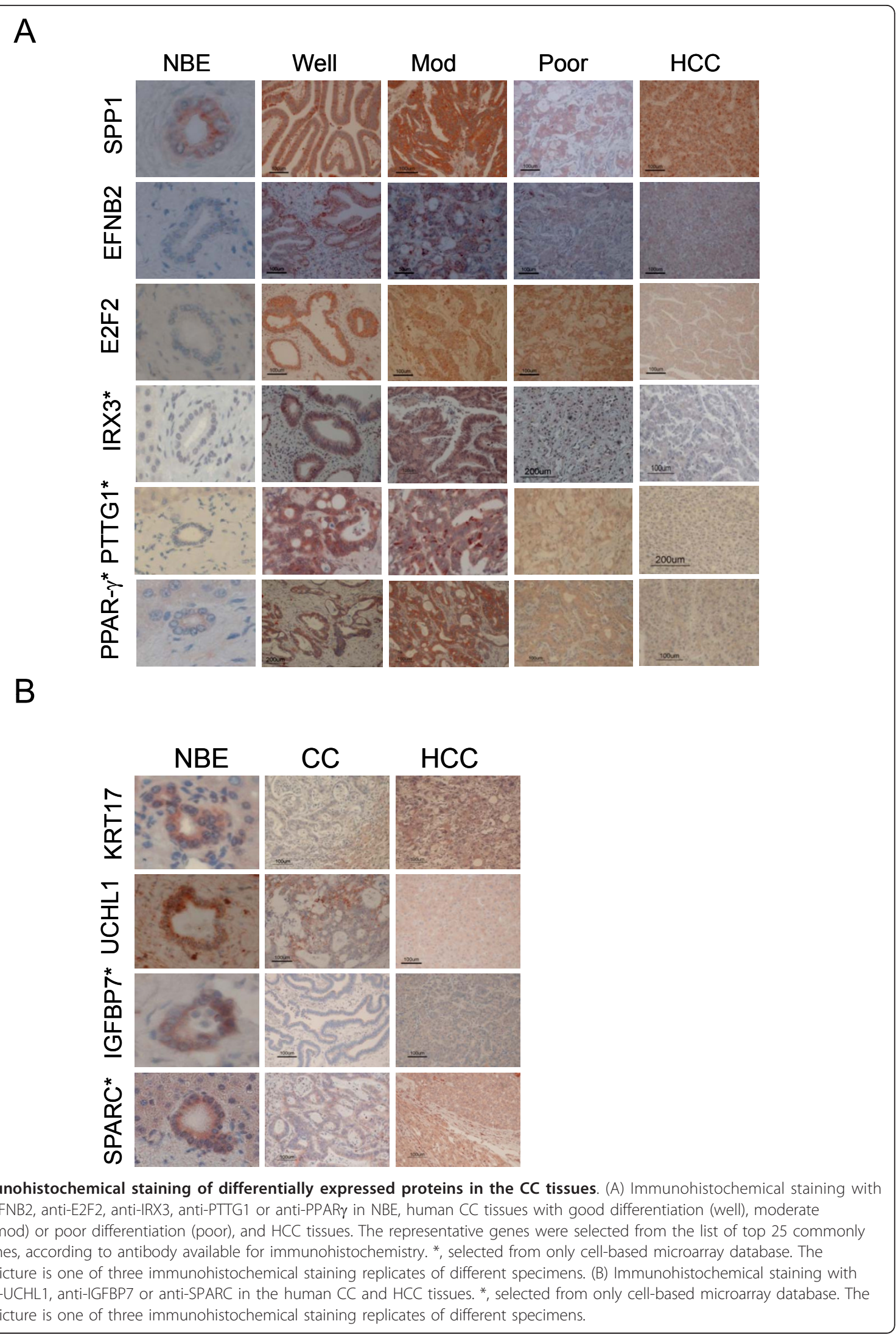

Figure 4 Immunohistochemical staining of differentially expressed proteins in the CC tissues. (A) Immunohistochemical staining with anti-SPP1, anti-EFNB2, anti-E2F2, anti-IRX3, anti-PTTG1 or anti-PPAR $\gamma$ in NBE, human CC tissues with good differentiation (well), moderate differentiation (mod) or poor differentiation (poor), and HCC tissues. The representative genes were selected from the list of top 25 commonly upregulated genes, according to antibody available for immunohistochemistry. ${ }^{*}$, selected from only cell-based microarray database. The representative picture is one of three immunohistochemical staining replicates of different specimens. (B) Immunohistochemical staining with anti-KRT-17, anti-UCHL1, anti-IGFBP7 or anti-SPARC in the human CC and HCC tissues. *, selected from only cell-based microarray database. The representative picture is one of three immunohistochemical staining replicates of different specimens. 


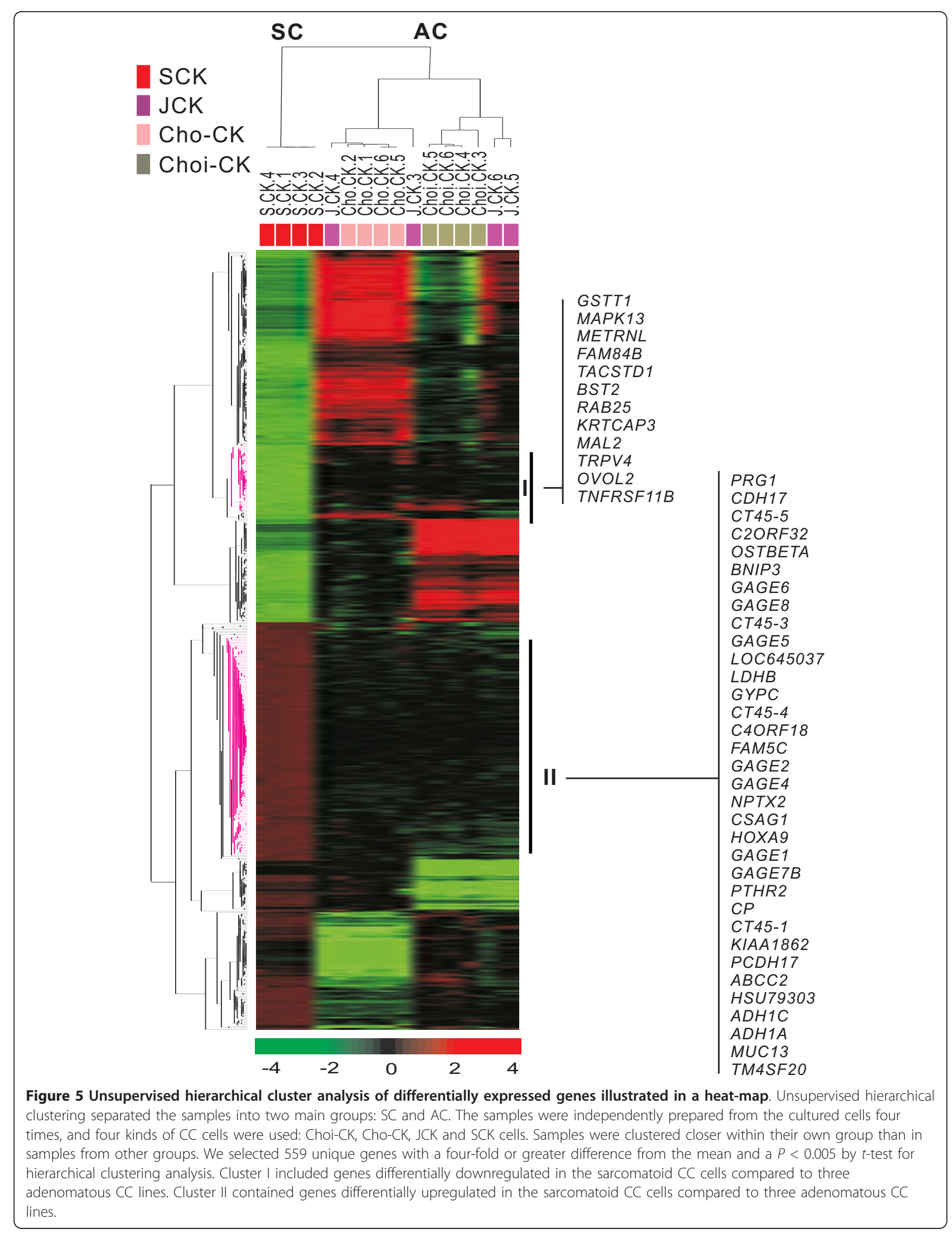


separated into two main groups, sarcomatoid (SC) and ordinary or adenocarcinomatous CC (AC), by the gene axis. The SC group contained 292 differentially upregulated genes ( $>$ four-fold change), and 267 downregulated genes $(<0.25$-fold change), compared to the AC group. The top 25 genes that were differentially expressed in the sarcomatoid SCK cells compared to the three adenocarcinomatous CC lines are in Additional file 6. Clustering data within groups revealed that the core clusters I and II were associated with transdifferentiation. Genes in cluster I appeared to be downregulated in the SCK cells, compared to ordinary CC cells. In contrast, the genes in cluster II were upregulated in the SCK cells and downregulated in the ordinary CC cells. Cluster I contained the GSTT1, TACSTD, BST2, RAB25, and MAL2 genes. Cluster II contained genes associated with tumor progression and metastasis, including $H O X A 9, M U C 13$, and members of the GAGE and CT-45 families [35-38]. Expression of methylation-silenced genes, such as $L D H B$, BNIP3, UCHL1, and NPTX2 [39-42], was barely detectable in the AC group, but appeared in this cluster.

\section{Expressions of transdifferentiation-related genes}

From 559 genes that were differentially regulated between SCK cells and the three ordinary CC lines, we selected six upregulated genes and six downregulated genes, and examined their mRNA expression using realtime RT-PCR (Figure 6A), which verified the differential expression. We examined protein expression by Western blot analysis of the four CC lines. LDHB, Bnip3, HO-1, and UCHL1 were overexpressed exclusively in SCK cells. The expression of VIM and TWIST1 increased according to tumor dedifferentiation and was highest in SCK cells (Figure 6B, left). In contrast, LCN2, S100P, KRT7, KRT19, GPX1, and EFNA1 were preferentially expressed in Choi-CK, Cho-CK and JCK cells, but minimally expressed in SCK cells (Figure 6B, right). Because $L D H B, B N I P 3$, and $U C H L 1$ are well-known methylationsilenced genes in tumors [39-41], and are highly expressed in SCK cells, this suggested that DNA demethylation was involved in CC. To confirm this hypothesis, we treated the AC cells with the demethylating agent Aza, which dramatically restorated expression of the silenced UCHL1 gene in these cells (Figure 6C). In addition, we performed immunohistochemical examination of protein expression according to tumor dedifferentiation in human CC tissue (Figure 6D). As expected, HO-1 was exclusively overexpressed in SC, while TWIST1 was overexpressed in the poorly differentiated and SC cells. In contrast, LCN2 was exclusively downregulated in SC, while EFNA1 expression decreased with tumor dedifferentiation. Therefore, expression of these proteins clearly correlated with clinicopathological features such as tumor differentiation and EMT change, in CC tissues.

\section{Discussion}

In this study, our experimental design primarily investigated the gene expression profiles of 10 cell lines and 19 $\mathrm{CC}$ tissues, and compared these profiles to those from four cultured NBE cell line using genome-wide BeadChip microarray analysis. Transdifferentiation-related genes were analyzed by same method. Using unsupervised hierarchical clustering analysis, we found that the $S P P 1, E F N B 2$, and $E 2 F$ genes were commonly upregulated in both cell and tissue samples. IRX3, PTTG1, and $P P A R \gamma$ were upregulated in the cell samples, and were immunohistochemically verified in human and hamster CC tissues. SPP1 (osteopontin), a secretory adhesive alycoprotein, was identified as a highly overexpressed gene in CC lines and tissues. SPP1 is a ligand of CD44 that binds to $\alpha \mathrm{V}$-containing integrins and is important in malignant cell attachment and tumor invasion [43]. It was a highly overexpressed gene in HCC, and its expression correlated with earlier recurrence, poorer prognosis, and metastasis [44]. Consistent with our findings, a recent oligonucleotide microarray study reported that SPP1 was the most highly expressed gene in intrahepatic cholangiocarcinoma [45]. EFNB2 was identified as a preferentially expressed genes in CC. EFNB2 overexpression is reported to be significantly correlated with the number of lymph node metastases and clinical stage in esophageal cancer [46]. Several reports have examined concomitant expression of the ligand EFNB2 and its receptor EphB4 in leukemia-lymphoma cell lines [47], and in endometrial cancer [48]. E2Fs 1-3 are characterized as "activator E2Fs" since their binding to promoters results in increased transcription, while E2Fs 4 and 5 are "repressor E2Fs" since they form complexes with p130, HDACs, and other factors to block transcription [49]. During hepatocarcinogenesis in c-myc/TGFalpha double-transgenic mice, expression of E2F-1 and E2F-2 increases, and putative E2F target genes are induced [50].

For immunohistochemical verification, the representative genes were selected from the list of top 25 commonly upregulated genes, according to antibody available for immunohistochemistry. In addition, other genes were selected from only cell-based microarray database. The same immunohistochemical staining in hamster CC tissues induced by Clonorchiasis infestation was compared with control staining in normal hamster livers. IRX3 is involved in dorsal-ventral patterning in spinal cord development and coordination with other homeobox genes [51]. IRX3 is preferentially expressed in the examined CC tissues and localized to the nucleus 
A

B
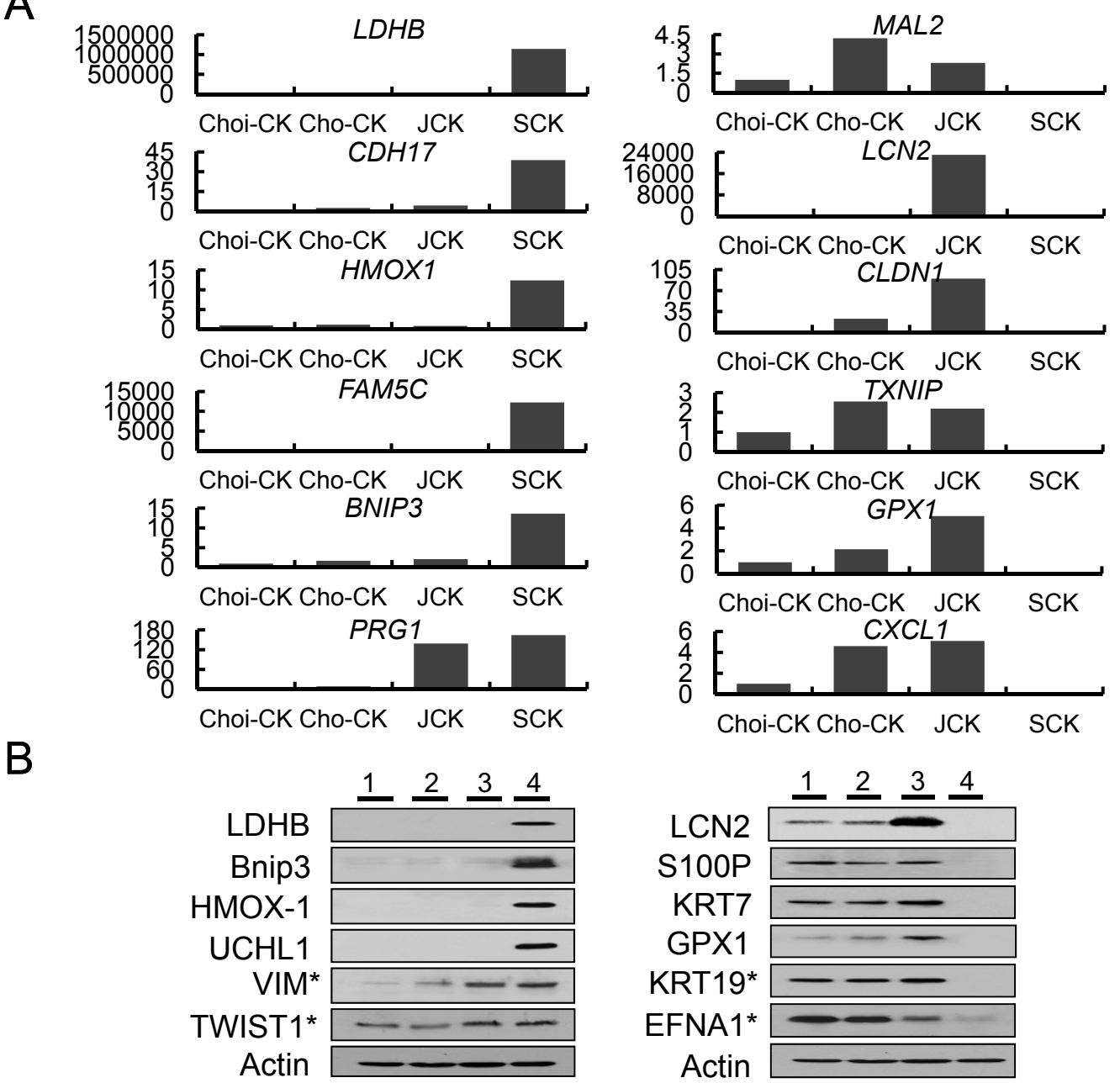

C

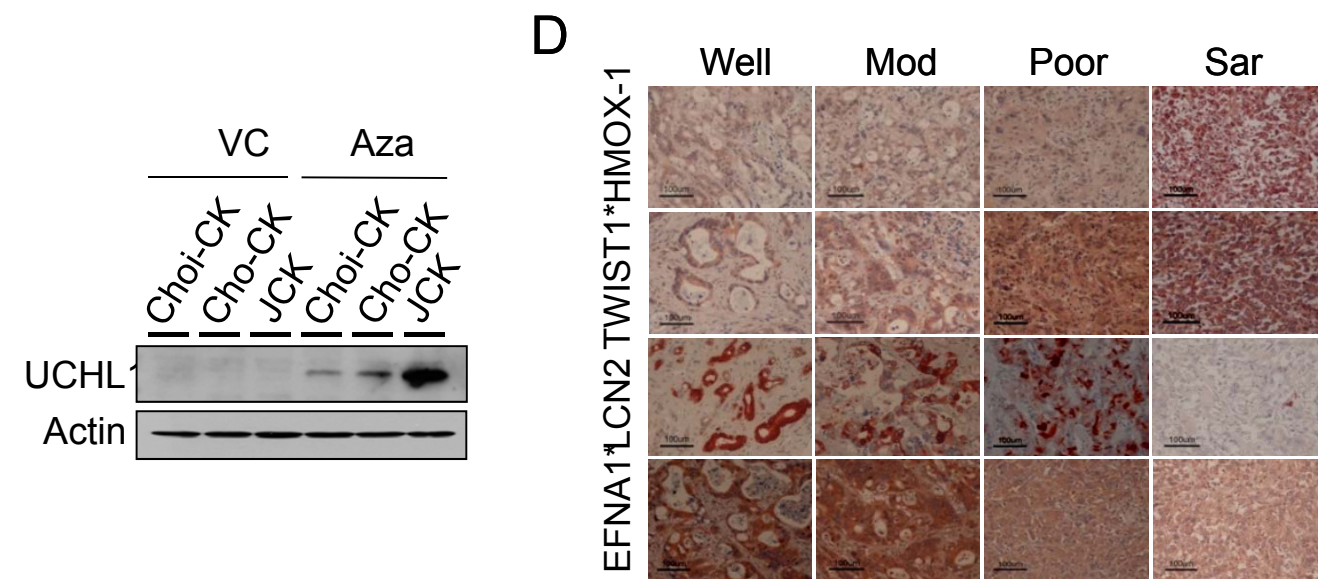

Figure 6 Genes and proteins differentially expressed in sarcomatoid CC and adenomatous CC cells. (A) Real-time RT-PCR analysis of upregulated (left) and downregulated (right) genes selected from the list of top 25 genes differentially expressed in sarcomatoid SCK cells and three adenocarcinomatous CC cell lines. (B) Immunoblot of upregulated (left) and down-regulated (right) proteins in sarcomtoid SCK cells compared to three adenocarcinomatous CC cell lines. ${ }^{*}$, selected from the top 100 genes differentially expressed in sarcomatoid SCK cells compared to three adenocarcinomatous CC cell lines. Lane 1, Choi-CK cells. Lane 2, Cho-CK cells. Lane 3, JCK cells, Lane 4, SCK cells. (C) Immunoblot of UCHL1. Expression was restored in adenocarcimatous CC cells by treatment of $5 \mu \mathrm{M}$ of Aza for 4 days, compared to vehicle control (VC). (D) Immunohistochemical staining of down- or upregulated proteins according to tumor dedifferentiation. The representative picture is one of three immunohistochemical staining replicates of different specimens. Well, well-differentiated CC. Mod, moderately differentiated CC. Poor, poorly differentiated CC. Sar, sarcomatoid CC. *, selected from the top 100 genes differentially expressed in sarcomatoid SCK cells compared to three adenocarcinomatous CC cell lines. 
of human and hamster malignant biliary epithelial cells, independent of cell differentiation. A methylated CpG island was detected in exon 2 of the IRX3 locus, rather than in the promoter, and is responsible for IRX3 overexpression in brain tumor cells and tissues [52]. PTTG1, a critical mitotic checkpoint protein, is a known protooncogene that is highly expressed in HCC [53]. Our data showed that PTTG1 was preferentially expressed in the cytoplasm of the human and hamster CC cells. PPAR- $\gamma$, a member of the nuclear receptor superfamily, functions as a ligand-activated transcription factor [54]. It is overexpressed in a variety of cancers, including HCC and pancreatic cancer $[55,56]$. Positive immunostaining was localized in the cytoplasm and nuclei of human CC cells. However, positive immunostaining was exclusively detected in the nuclei of the hamster CC cells. Our data also immunohistochemically validated the downregulation of proteins KRT17, UCHL1, IGFBP7, and SPARC. Our hamster model showed the similar expression patterns of human CC related genes and therefore might be a relevant model to study human CC.

Analysis of genes involved in the transdifferentiation of CC cells showed two clusters in the gene axis, with genes that were upregulated (cluster II), and downregulated (cluster I) in the SC group as compared to the $\mathrm{AC}$ group. The mesenchymal antigen VIM and the transcriptional factor TWIST1 were upregulated in JCK and SCK cells by tumor dedifferentiation. The overexpression of these proteins is reported to be associated with the EMT $[57,58]$. Intriguingly, genes silenced by promoter hypermethylation during CC development were restored at the point of sarcomatous transdifferentation, which implied that the demethylation may be involved in the EMT progression of CC.

In addition to tumor-related genes known to be overexprssed in intrahepatic $\mathrm{CC}$, we identified other strongly and consistently dysregulated genes in $\mathrm{CC}$ that are known to be involved in other human cancers. Our data support a correlation between the expression of these genes and CC tumor differentiation, and the gene expression patterns found in this study are consistent with those associated with a poor clinical prognosis for this cancer. gene expression profiling appears to be a useful diagnostic tool, especially for differentiating CC from other liver masses, as well as for the subclassification of intrahepatic CC compared to histopathological findings.

\section{Conclusions}

Gene expression profiling appears to be a useful diagnostic tool, especially for differentiating CC from other liver masses, as well as for the subclassification of intrahepatic CC compared to histopathological findings. The most consistently overexpressed genes are candidate therapeutic targets, and related genes can be used for predicting survival and outcomes for different therapeutic modalities.

\section{Additional material}

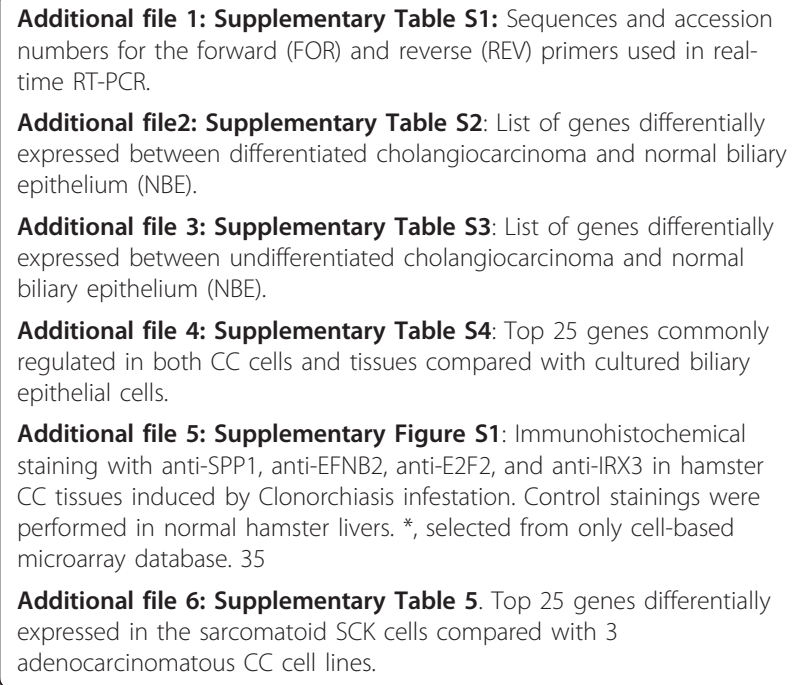

Additional file2: Supplementary Table S2: List of genes differentially expressed between differentiated cholangiocarcinoma and normal biliary epithelium (NBE).

Additional file 3: Supplementary Table S3: List of genes differentially expressed between undifferentiated cholangiocarcinoma and normal biliary epithelium (NBE).

Additional file 4: Supplementary Table S4: Top 25 genes commonly regulated in both CC cells and tissues compared with cultured biliary epithelial cells.

Additional file 5: Supplementary Figure S1: Immunohistochemical staining with anti-SPP1, anti-EFNB2, anti-E2F2, and anti-IRX3 in hamster CC tissues induced by Clonorchiasis infestation. Control stainings were performed in normal hamster livers. ${ }^{*}$, selected from only cell-based microarray database. 35

Additional file 6: Supplementary Table 5. Top 25 genes differentially expressed in the sarcomatoid SCK cells compared with 3

adenocarcinomatous CC cell lines.

\section{Acknowledgements}

We gratefully thank Prof. Yoon B-I (Kangwon National University, South Korea) for providing the hamster CC tissues. This study was supported by grants from the Korean Association of Internal Medicine (Chungram Research Fund, 1997), a Korea Research Foundation grant from the Korean government (Basic Research Promotion Fund, KRF-2008-313-E00434), and the National R\&D Program for Cancer Control (0620220) and the Korean Health Technology R\&D Project (A101834), Ministry for Health, Welfare and Family affairs (0620220), Republic of Korea.

\section{Author details}

'Division of Gastroenterology and Hepatology, the Institute for Medical Science, Departments of Internal Medicine, Chonbuk National University Medical School and Hospital, Jeonju, Jeonbuk, South Korea. ${ }^{2}$ Department of Surgery, Chonbuk National University Medical School and Hospital, Jeonju, Jeonbuk, South Korea. ${ }^{3}$ Medical Genomics Research Center, Korea Research Institute of Bioscience and Biotechnology, Daejeon 305-806, South Korea. ${ }^{4}$ Department of Biological Science, Dong-A University, Busan 604-714, South Korea.

\section{Authors' contributions}

MS and IC performed most of the experiments and drafted the manuscript. $\mathrm{ML}$ and GY carried out the tissue collection and the establishment of cell lines. XC participated in the immunohistochemical analysis. BC and IK participated in the design and coordination of the study and helped to draft the manuscript. EA and SL participated in the array data processing and analysis. DK conceived of the study, and participated in its design and coordination. All authors read and approved the final manuscript.

\section{Competing interests}

The authors declare that they have no competing interests.

Received: 12 December 2009 Accepted: 19 February 2011

Published: 19 February 2011

\section{References}

1. Shaib YH, Davila JA, McGlynn K, El-Serag HB: Rising incidence of intrahepatic cholangiocarcinoma in the United States: a true increase? J Hepatol 2004, 40:472-477. 
2. Blendis $L$, Halpern Z: An increasing incidence of cholangiocarcinoma: why? Gastroenterology 2004, 127:1008-1009.

3. Mittal B, Deutsch M, Iwatsuki S: Primary cancers of extrahepatic biliary passages. Int J Radiat Oncol Biol Phys 1985, 11:849-854.

4. Pitt HA, Nakeeb A, Abrams RA, Coleman J, Piantadosi S, Yeo CJ, Lillemore KD, Cameron JL: Perihilar cholangiocarcinoma. Postoperative radiotherapy does not improve survival. Ann Surg 1995, 221:788-797.

5. Vauthey JN, Blumgart LH: Recent advances in the management of cholangiocarcinomas. Semin Liver Dis 1994, 14:109-114.

6. Gores GJ: Cholangiocarcinoma: current concepts and insights. Hepatology 2003, 37:961-969.

7. Ohashi K, Nakajima Y, Kanehiro H, Tsutsumi M, Taki J, Aomatsu Y, Yoshimura A, Ko S, Kin T, Yagura K, Konishi Y, Nakano H: Ki-ras mutations and $\mathrm{p} 53$ protein expressions in intrahepatic cholangiocarcinomas: relation to gross tumor morphology. Gastroenterology 1995, 109:1612-1617.

8. Furubo S, Harada K, Shimonishi T, Katayanagi K, Tsui W, Nakanuma Y: Protein expression and genetic alterations of p53 and ras in intrahepatic cholangiocarcinoma. Histopathology 1999, 35:230-240.

9. Tannapfel A, Sommerer F, Benicke M, Katalinic A, UhImann D, Witzigmann $\mathrm{H}$, Hauss J, Wittekind C: Mutations of the BRAF gene in cholangiocarcinoma but not in hepatocellular carcinoma. Gut 2003, 52:706-712.

10. Endo $\mathrm{K}$, Yoon Bl, Pairojkul C, Demetris AJ, Sirica AE: ERBB-2 overexpression and cyclooxygenase-2 up-regulation in human cholangiocarcinoma and risk conditions. Hepatology 2002, 36:439-450.

11. Sugawara H, Yasoshima M, Katayanagi K, Kono N, Watanabe Y, Harada K, Nakanuma Y: Relationship between interleukin- 6 and proliferation and differentiation in cholangiocarcinoma. Histopathology 1998, 33:145-153.

12. Xu X, Kobayashi S, Qiao W, Li C, Xiao C, Radaeva S, Stiles B, Wang RH, Ohara N, Yoshino T, LeRoith D, Torbenson MS, Gores GJ, Wu H, Gao B, Deng CX: Induction of intrahepatic cholangiocellular carcinoma by liverspecific disruption of Smad4 and Pten in mice. J Clin Invest 2006, 116:1843-1852.

13. Nakajima T, Tajima Y, Sugano I, Nagao K, Kondo Y, Wada K: Intrahepatic cholangiocarcinoma with sarcomatous change. Clinicopathologic and immunohistochemical evaluation of seven cases. Cancer 1993, 72:1872-1877.

14. Aishima S, Kuroda Y, Asayama Y, Taguchi K, Nishihara Y, Taketomi A, Tsuneyoshi M: Prognostic impact of cholangiocellular and sarcomatous components in combined hepatocellular and cholangiocarcinoma. Hum Pathol 2006, 37:283-291.

15. Hansel DE, Rahman A, Hidalgo M, Thuluvath PJ, Lillemoe KD, Shulick R, Ku JL, Park JG, Miyazaki K, Ashfaq R, Wistuba II, Varma R, Hawthorne L, Geradts J, Argani P, Maitra A: Identification of novel cellular targets in biliary tract cancers using global gene expression technology. Am J Pathol 2003, 163:217-229.

16. Obama K, Ura K, Li M, Katagiri T, Tsunoda T, Nomura A, Satoh S, Nakamura Y, Furukawa Y: Genome-wide analysis of gene expression in human intrahepatic cholangiocarcinoma. Hepatology 2005, 41:1339-1348.

17. Kim DG, Park SY, You KR, Lee GB, Kim H, Moon WS, Chun YH, Park SH: Establishment and characterization of chromosomal aberrations in human cholangiocarcinoma cell lines by cross-species color banding. Genes Chromosomes Cancer 2001, 30:48-56.

18. Makuuchi M, Belghiti J, Belli G, Fan ST, Lau JW, Ringe B, Strasberg SM, Vauthey JN, Yamaoka Y, Yamasaki S, Working Group of the International Scientific Committee of the International Hepato-Pancreato-Biliary Association: IHPBA concordant classification of primary liver cancer: working group report. J Hepatobiliary Pancreat Surg 2003, 10:26-30.

19. Lee MJ, Yu GR, Park SH, Cho BH, Ahn JS, Park HJ, Song EY, Kim DG: Identification of cystatin B as a potential serum marker in hepatocellular carcinoma. Clin Cancer Res 2008, 14:1080-1089.

20. Yoon Bl, Kim DY, Jang JJ, Han JH: Altered expression of thioredoxin reductase-1 in dysplastic bile ducts and cholangiocarcinoma in a hamster model. J Vet Sci 2006, 7:211-216.

21. Gao Y, Kitagawa K, Hiramatsu Y, Kikuchi H, Isobe T, Shimada M, Uchida C, Hattori T, Oda T, Nakayama K, Nakayama Kl, Tanaka T, Konno H, Kitagawa M: Up-regulation of GPR48 induced by down-regulation of p27Kip1 enhances carcinoma cell invasiveness and metastasis. Cancer Res 2006, 66:11623-11631
22. Wang Z, Hao Y, Lowe AW: The Adenocarcinoma-associated antigen, AGR2, promotes tumor growth, cell migration, and cellular transformation. Cancer Res 2008, 68:492-497.

23. Ge X, Jin Q, Zhang F, Yan T, Zhai Q: PCAF acetylates \{beta\}-catenin and improves its stability. Mol Biol Cell 2009, 20:419-427.

24. Moparthi SB, Arbman G, Wallin A, Kayed H, Kleeff J, Zentgraf H, Sun XF: Expression of MAC30 protein is related to survival and biological variables in primary and metastatic colorectal cancers. Int J Oncol 2007, 30:91-95.

25. Saitoh T, Katoh M: FRAT1 and FRAT2, clustered in human chromosome 10q24.1 region, are up-regulated in gastric cancer. Int J Oncol 2001, 19:311-315.

26. Tachibana M, Tonomoto Y, Hyakudomi R, Hyakudomi M, Hattori S, Ueda S, Kinugasa S, Yoshimura H: Expression and prognostic significance of EFNB2 and EphB4 genes in patients with oesophageal squamous cell carcinoma. Dig Liver Dis 2007, 39:725-732.

27. Bidus MA, Risinger Jl, Chandramouli GV, Dainty LA, Litzi TJ, Berchuck A, Barrett JC, Maxwell GL: Prediction of lymph node metastasis in patients with endometrioid endometrial cancer using expression microarray. Clin Cancer Res 2006, 12:83-88.

28. Chen B, Athanasiou M, Gu Q, Blair DG: Drm/Gremlin transcriptionally activates p21(Cip1) via a novel mechanism and inhibits neoplastic transformation. Biochem Biophys Res Commun 2002, 295:1135-1141.

29. Abeysinghe HR, Cao Q, Xu J, Pollock S, Veyberman Y, Guckert NL, Wang N: HY1 expression is associated with tumor suppression of human ovarian cancer. Cancer Genet Cytogenet 2003, 143:125-132.

30. Gagliardi AD, Kuo EY, Raulic S, Wagner GF, DiMattia GE: Human stanniocalcin-2 exhibits potent growth-suppressive properties in transgenic mice independently of growth hormone and IGFs. Am J Physiol Endocrinol Metab 2005, 288:E92-105.

31. Shetty S, Shetty P, Idell S, Velusamy T, Bhandary YP, Shetty RS: Regulation of plasminogen activator inhibitor- 1 expression by tumor suppressor protein p53. J Biol Chem 2008, 283:19570-19580.

32. Esposito I, Kayed H, Keleg S, Giese T, Sage EH, Schirmacher P, Friess H, Kleeff J: Tumor-suppressor function of SPARC-like protein $1 /$ Hevin in pancreatic cancer. Neoplasia 2007, 9:8-17.

33. Yang Z, Chang YJ, Miyamoto H, Ni J, Niu Y, Chen Z, Yao JL, di Sant'Agnese PA, Chang C: Transgelin functions as a suppressor via inhibition of ARA54-enhanced androgen receptor transactivation and prostate cancer cell growth. Mol Endocrinol 2007, 21:343-358.

34. Yoo HJ, Yun BR, Kwon JH, Ahn HS, Seol MA, Lee MJ, Yu GR, Yu HC, Hong B, Choi K, Kim DG: Genetic and expression alterations in association with the sarcomatous change of cholangiocarcinoma cells. Exp Mol Med 2009, 41:102-115.

35. Tedeschi FA, Zalazar FE: HOXA9 gene expression in the chronic myeloid leukemia progression. Leuk Res 2006, 30:1453-1456.

36. Walsh MD, Young JP, Leggett BA, Williams SH, Jass JR, McGuckin MA: The MUC13 cell surface mucin is highly expressed by human colorectal carcinomas. Hum Pathol 2007, 38:883-892.

37. Kong U, Koo J, Choi K, Park J, Chang H: The expression of GAGE gene can predict aggressive biologic behavior of intestinal type of stomach cancer. Hepatogastroenterology 2004, 51:1519-1523.

38. Chen YT, Scanlan MJ, Venditti CA, Chua R, Theiler G, Stevenson BJ, Iseli C, Gure AO, Vasicek T, Strausberg RL, Jongeneel CV, Old L, Simpson AJ: Identification of cancer/testis-antigen genes by massively parallel signature sequencing. Proc Natl Acad Sci USA 2005, 102:7940-7945.

39. Leiblich A, Cross SS, Catto JW, Phillips JT, Leung HY, Hamdy FC, Rehman I: Lactate dehydrogenase- $B$ is silenced by promoter hypermethylation in human prostate cancer. Oncogene 2006, 25:2953-2960.

40. Abe T, Toyota M, Suzuki H, Murai M, Akino K, Ueno M, Nojima M, Yawata A, Miyakawa $\mathrm{H}$, Suga $\mathrm{T}$, Ito $\mathrm{H}$, Endo T, Tokino T, Hinoda $\mathrm{Y}$, Imai $\mathrm{K}$ : Upregulation of 23BNIP3 by 5-aza-2'-deoxycytidine sensitizes pancreatic cancer cells to hypoxia-mediated cell death. I Gastroenterol 2005, 40:504-510.

41. Yu J, Tao Q, Cheung KF, Jin H, Poon FF, Wang X, Cheng YY, Röcken C, Ebert MP, Chan AT, Sung JJ: Epigenetic identification of ubiquitin carboxyl-terminal hydrolase $\mathrm{L} 1$ as a functional tumor suppressor and biomarker for hepatocellular carcinoma and other digestive tumors. Hepatology 2008, 48:508-518.

42. Sato N, Fukushima N, Maitra A, Matsubayashi H, Yeo CJ, Cameron JL, Hruban RH, Goggins M: Discovery of novel targets for aberrant 
methylation in pancreatic carcinoma using high-throughput microarrays. Cancer Res 2003, 63:3735-3742.

43. Harada N, Mizoi T, Kinouchi M, Hoshi K, Ishii S, Shiiba K, Sasaki I, Matsuno S: Introduction of antisense CD44S CDNA down-regulates expression of overall CD44 isoforms and inhibits tumor growth and metastasis in highly metastatic colon carcinoma cells. Int J Cancer 2001, 91:67-75.

44. Pan HW, Ou YH, Peng SY, Liu SH, Lai PL, Lee PH, Sheu JC, Chen CL, Hsu HC Overexpression of osteopontin is associated with intrahepatic metastasis, early recurrence, and poorer prognosis of surgically resected hepatocellular carcinoma. Cancer 2003, 98:119-127.

45. Hass HG, Nehls O, Jobst J, Frilling A, Vogel U, Kaiser S: Identification of osteopontin as the most consistently over-expressed gene in intrahepatic cholangiocarcinoma: Detection by oligonucleotide microarray and real-time PCR analysis. World I Gastroenterol 2008, 14:2501-2510.

46. Tachibana M, Tonomoto $Y$, Hyakudomi R, Hyakudomi M, Hattori S, Ueda S, Kinugasa S, Yoshimura H: Expression and prognostic significance of EFNB2 and EphB4 genes in patients with oesophageal squamous cell carcinoma. Dig Liver Dis 2007, 39:725-732.

47. Steube KG, Meyer C, Habig S, Uphoff CC, Drexler HG: Expression of receptor tyrosine kinase HTK (hepatoma transmembrane kinase) and HTK ligand by human leukemia-lymphoma cell lines. Leuk Lymphoma 1999, 33:371-376.

48. Takai N, Miyazaki T, Fujisawa K, Nasu K, Miyakawa I: Expression of receptor tyrosine kinase EphB4 and its ligand ephrin-B2 is associated with malignant potential in endometrial cancer. Oncol Rep 2001, 8:567-573.

49. Ren B, Cam H, Takahashi Y, Volkert T, Terragni J, Young RA, Dynlacht BD: $\mathrm{E} 2 \mathrm{~F}$ integrates cell cycle progression with DNA repair, replication, and G (2)/M checkpoints. Genes Dev 2002, 16:245-256.

50. Surawska H, Ma PC, Salgia R: The role of ephrins and Eph receptors in cancer. Cytokine Growth Factor Rev 2004, 15:419-4133.

51. Kudoh T, Dawid IB: Role of the iroquois3 homeobox gene in organizer formation. Proc Natl Acad Sci USA 2001, 98:7852-7857.

52. Ordway JM, Bedell JA, Citek RW, Nunberg A, Garrido A, Kendall R, Stevens JR, Cao D, Doerge RW, Korshunova Y, Holemon H, McPherson JD, Lakey N, Leon J, Martienssen RA, Jeddeloh JA: Comprehensive DNA methylation profiling in a human cancer genome identifies novel epigenetic targets. Carcinogenesis 2006, 27:2409-2423.

53. Cho-Rok J, Yoo J, Jang YJ, Kim S, Chu IS, Yeom YI, Choi JY, Im DS: Adenovirus-mediated transfer of siRNA against PTTG1 inhibits liver cancer cell growth in vitro and in vivo. Hepatology 2006, 43:1042-1052.

54. Issemann I, Green S: Activation of a member of the steroid hormone receptor superfamily by peroxisome proliferators. Nature 1990, 347:645-650.

55. Schaefer KL, Wada K, Takahashi H, Matsuhashi N, Ohnishi S, Wolfe MM, Turner JR, Nakajima A, Borkan SC, Saubermann LJ: Peroxisome proliferatoractivated receptor gamma inhibition prevents adhesion to the extracellular matrix and induces anoikis in hepatocellular carcinoma cells. Cancer Res 2005, 65:2251-2259.

56. Kristiansen G, Jacob J, Buckendahl AC, Grützmann R, Alldinger I, Sipos B, Klöppel G, Bahra M, Langrehr JM, Neuhaus P, Dietel M, Pilarsky C: Peroxisome proliferator-activated receptor $\gamma$ is highly expressed in pancreatic cancer and is associated with shorter overall survival times. Clinical Cancer Research 2006, 12:6444-6451.

57. Dandachi N, Hauser-Kronberger C, Moré E, Wiesener B, Hacker GW, Dietze $\mathrm{O}$, Wirl G: Co-expression of tenascin- $\mathrm{C}$ and vimentin in human breast cancer cells indicates phenotypic transdifferentiation during tumour progression: correlation with histopathological parameters, hormone receptors, and oncoproteins. J Pathol 2001, 193:181-189.

58. Lee TK, Poon RT, Yuen AP, Ling MT, Kwok WK, Wang XH, Wong YC, Guan XY, Man K, Chau KL, Fan ST: Twist overexpression correlates with hepatocellular carcinoma metastasis through induction of epithelialmesenchymal transition. Clin Cancer Res 2006, 12:5369-5376.

\section{Pre-publication history}

The pre-publication history for this paper can be accessed here: http://www.biomedcentral.com/1471-2407/11/78/prepub

doi:10.1186/1471-2407-11-78

Cite this article as: Seol et al:: Genome-wide expression patterns associated with oncogenesis and sarcomatous transdifferentation of cholangiocarcinoma. BMC Cancer 2011 11:78.

\section{Submit your next manuscript to BioMed Central and take full advantage of:}

- Convenient online submission

- Thorough peer review

- No space constraints or color figure charges

- Immediate publication on acceptance

- Inclusion in PubMed, CAS, Scopus and Google Scholar

- Research which is freely available for redistribution

Submit your manuscript at www.biomedcentral.com/submit
Biomed Central 